University of New Mexico

UNM Digital Repository

Shared Knowledge Conference

Nov 7th, 2:00 PM - 3:45 PM

Promoting Social-Emotional Learning Through Physical Activity

Caitlin Olive

Karen Lux Gaudreault

Bryan A. McCullick

Phillip Tomporowski

Follow this and additional works at: https://digitalrepository.unm.edu/skc 


\title{
Promoting Social-Emotional Learning Through Physical Activity
}

\author{
Caitlin Olive \\ Department of Health, Exercise, and Sports Sciences \\ University of New Mexico \\ Karen Lux Gaudreault \\ Department of Health, Exercise, and Sports Sciences \\ University of New Mexico \\ Bryan A. McCullick \\ Department of Kinesiology \\ University of Georgia \\ Phillip Tomporowski \\ Department of Kinesiology \\ University of Georgia
}

Social-emotional learning has become an increasingly popular topic in education as today's students are expected to attend to an exceeding amount of expectations, such as academic achievement, responsible decision making, cooperating with others, and resisting negative tendencies (Elias et al., 1997). SEL is founded on the notion that social-emotional learning and academic achievement are interdependent and should be deliberately taught in order to maximize student learning (Greenberg et al., 2003). Accordingly, CASEL developed guides for implement district wide SEL programming to ensure competencies are taught across subject areas (Durlak et al., 2011). SEL programs can occur during the school day or within after-school programs (ASPs). Many ASPs include physical activity (PA) as an important component in program time often in the form of unstructured free play type. However, if PA is structured with planned activities, developed routines, and academic language (i.e. SEL concepts), similar to best practices within physical education (PE), it can provide opportunities for SEL skill development. Therefore, the purpose of this session is to provide participants with a brief overview of SEL, how to teach SEL within PA contexts, and to present strategies and recommendations for implementing SEL and PA opportunities in after-school programs (ASPs). 